\title{
Gericault's Fake-Gallop Horse Judged Speedy but Unrealistic
}

\author{
Stefano Mastandrea ${ }^{1, *}$ and John M. Kennedy ${ }^{2}$ \\ ${ }^{1}$ University of Roma Tre, Rome, Italy \\ ${ }^{2}$ University of Toronto, Scarborough, Canada \\ Received 6 February 2018; accepted 23 April 2018
}

\begin{abstract}
In two experiments, we tested pictures of horse gaits—alt (standing), walk, trot, gallop, and a fake gallop, a pose shown in a well-known Gericault painting. The pose was portrayed frequently in the nineteenth century, its features hotly debated. Fake gallop has legs extended fore and rear, close to parallel to the ground. Experiment 1 sampled real artworks depicting horses and Experiment 2 used silhouettes of horses. In both, reports of amount of movement increased from alt to fake gallop. In Experiment 1 similar results were obtained from novices and equestrians ('experts' familiar with horses). The extreme leg extension in fake gallop may suggest high speed, as Arnheim suggested. However, true gallop includes legs curled close together under the body - a 'running pony' pose - so both extremes of extension may suggest high speed. In Experiment 2, novices judged fake gallop unrealistic despite giving high movement scores. We suggest its depiction may be metaphoric, meaning a deliberately false item has relevant features of a referent. For the artworks, the amount of movement reported correlated positively but quite modestly with aesthetic appreciation, but for the silhouettes, the correlation was reversed. We suggest expression can be positive for many horse poses.
\end{abstract}

\section{Keywords}

Static pictures, implied motion, extension, horse gaits, metaphor

\section{Introduction}

A static picture can be seen as a 'freeze frame' of an action, with implied motion (Goldstein, 2007; Dobrez, 2013). In the Gericault 1821 painting The Epsom Derby (Fig. 1), the horses' legs are extended and rear legs appear to be in the air, as they fail to cast shadows on the ground that are contiguous

\footnotetext{
*To whom correspondence should be addressed. E-mail: stefano.mastandrea@uniroma3.it
} 


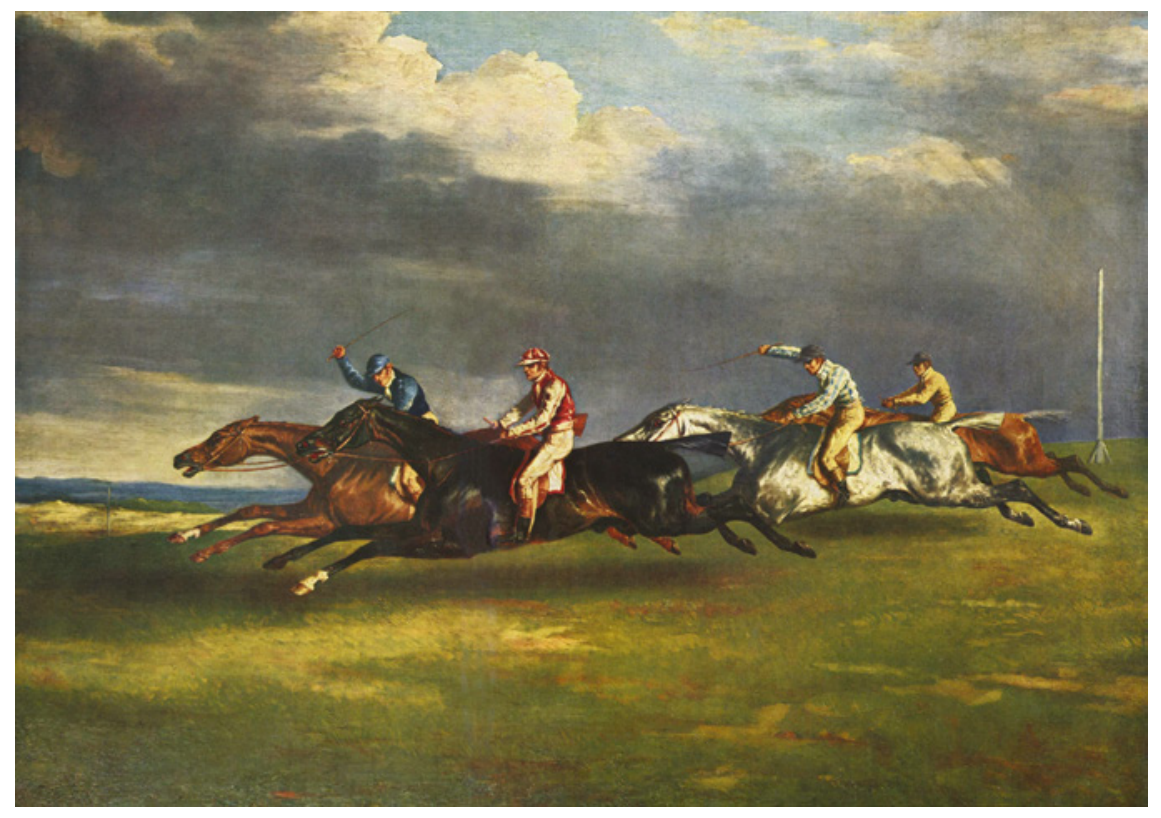

Figure 1. Gericault's painting The Epsom Derby, 1821. A 'maximum' spread of the legs may indicate a 'maximum' speed, Arnheim (1974) suggested. This is a fake gallop, because no running horse assumes this posture.

with the rear hooves. Gombrich (1995) wrote about this picture and other illustrations of the time "[Pictures showed horses] with outstretched legs in full flight through the air as the great nineteenth-century French painter Theodore Gericault painted them in a famous representation of the races at Epsom" (p. 28). The legs are also extended in a picture from 70 years before, one by James Seymour, The Chaise Match run on Newmarket Heath on Wednesday the $29^{\text {th }}$ of August 1750 (Vaughan, 1999, Fig. 113, p. 167), but the rear legs are shown as contacting the ground since their shadows touch the hooves. An art historian, Vaughan says of Seymour "like all painters before photography, he shows the legs of a galloping horse quite wrongly (p. 167)."

Commenting on artists of the period, Gombrich wrote "not one of these people seems to have noticed what it 'really looks like' when a horse runs" (Gombrich, 1995, p. 28). In a 1791 painting by George Stubbs (1724-1806) similar to the Gericault the horse's legs are shown extended fore and rear. In this case the rear legs are in such a dark area of the picture that information about their contact with the ground is unavailable. (The Stubbs picture, entitled Baronet with Sam Chifney Up, shows a horse called Baronet and a jockeySam Chifney. It is now located in the Huntingdon Museum, Pasadena, CA, USA). Stubbs was highly influential. "His clear-sighted combination of visual clarity and intellectual enquiry places him amongst the great visual artists on 
the Enlightenment," Vaughan (1999, p. 167) wrote, in his book entitled British Painting: the Golden Age. As in the Stubbs picture, in the Gericault horses are in a 'flying gallop' or 'fake gallop,' legs extended, and evidence from shadows indicates that the hooves are off the ground.

The Gericault pose is not only used in many pictures widespread in the early nineteenth century (Gombrich, 1964), in popular prints for example, it is still found in pictures on the walls of hotels and restaurants connected with horse racing in cities. In Dublin, for example, such nineteenth century prints are evident in O'Callaghan's Davenport Hotel near Merrion Square. In Toronto they are on the walls of Windfields Restaurant, near the one-time site of stables (E.P. Taylor's) with an international reputation (training Northern Dancer, notably, the winner of the 1964 Kentucky Derby and the Preakness, with a bloodline that includes more Breeder's Cup winners than any line from any other horse). Frequently these pictures are reprints of prints more than a century old. It is also in illustrations from the nineteenth century decorating Wikipedia text to do with the American Indian Wars, for example (American Indian Wars, n.d.). However, the pose is also found on contemporary brooches from designers such as The Finishing Touch of Kentucky.

A related pose with legs extended in extremis is adopted by bucking horses, though in this case the fore legs are on the ground and the rear legs are in the air (photo by Korol, 2017). A bucking horse has little in the way of forward motion. Steeplechase horses completing a leap over a fence and approaching landing sometimes have the fore legs close to the ground and the rear legs in the air. However, in the steeplechase leap, usually when the fore legs are extended the rear legs are curled under the body (Note 1). Further, in the landing the horse's body is strongly inclined, fore legs low and rear legs high, rather than horizontal as in the Gericault. In a leap, the fore legs are curled at the onset, and as the horse clears the fence. Then they extend, reaching toward the ground, and the rear legs curl forward and under the body. Unlike these cases, in the Gericault pose the horse's body is close to parallel to the ground, and the extension fore and aft of the legs is similar, the fore leg, from the forearm to below the knee and towards the hoof, making a shallow arc concave to the ground and the lower rear legs, below the hock, a similar arc convex to the ground. In a Finishing Touch of Kentucky brooch (labeled HPN 4311 6/12) two forelegs are straight rather than curved, and the base of a hoof of a front leg is tilted about 45 degrees. In the Gericault, the base of the front hoof is parallel to the ground and the base of the rear hoof faces backwards. In Windfields prints engraved by W. Summers (1871a, b-Tattenham Corner and The Winning Post, based on pictures by $\mathrm{H}$. Alken), the bases of the fore hoofs of the central horses are not parallel to the ground - they range from 20 to 30 degrees tilt.

If the jockeys, ground and shadows were stripped away, to the ordinary observer the Gericault pose may be ambiguous. The title of the picture specifies a race, specifically the Derby at Epsom. This indicates a galloping horse. 
However, taken out of their context the horse's limb extensions might be taken by observers as to do any of several motions, not just galloping. They might be taken as to do with a forward leap. Indeed, the posture might suggest jumping vertically into the air as if springing up like a cat, legs akimbo. It might mean bucking (as in Korol's newspaper illustration). A stretching motion is a possibility. It might even be taken as a pose of a horse lying down as if doing 'the splits,' a common posture of cats and dogs. In the Gericault, the pose is disambiguated by context, notably including the riders, shown as jockeys in racing colors and poses. Also, the shadows are mostly separated from the horses, not contiguous. Dark regions below the horses indicate the horses are off the ground. There is an exception: a dark patch below the foreground horse surrounds the nearest fore hoof, encompassing it. The patch is larger than a shadow would be, and it reaches forward from the horse. Since there is no small shadow below the fore hoof, and spatially separate from it, the picture offers some spatial ambiguity. (In the Summers (1871a,b) engravings, shadows separate from the hooves indicate they are off the ground).

Much discussed in the 1800-1870 era when the Gericault pose was widely adopted by artists was the conjecture that in a fast gallop all the horse's legs would lose contact with the ground. Of interest, "Seymour had a high reputation for the accuracy of his animal portraiture," notes Vaughan (1999, p. 167). Due to the rapidity of the motion, direct perception of galloping horses did not settle the question, which was concluded with the advent of stopped-motion photography, and its use by Eadweard Muybridge in 1878 (funded by wealthy industrialist Leland Stanford, who had proposed the horse did part company with the ground in a gallop). The answer to the off-the-ground conjecture is yes, but not in the Gericault manner. Rather, in a gallop, loss of contact with the ground occurs with the legs curling under the horse's body, a curled-leg pose used in the brand badge of the Ford Mustang - the 'running pony' badge. In the gallop, a front leg is the last to lose contact with the ground and to curl under. To a listener, the result is a rhythmic or drumming sound, with several loud beats from the hooves striking the ground, with very brief pauses between beats, and a slightly longer silence when the legs are in the air in the running-pony pose. In complete contrast to legs curling under the body, the so-called fake gallop of the Gericault horse is in full flight, legs extended fore and aft and off the ground.

Gombrich wrote "when painters began to apply [the Muybridge finding], and painted horses moving as they actually do [people] complained that that their pictures looked wrong" (1995, p. 28). However, why was there debate before Muybridge's work? In depiction of motion, why would an unrealistic pose be widely accepted, and yet energetically debated? One possibility is that it might be effective, but not deceptive. This is our own impression. If so, the picture is taken by the viewer as unrealistic, employing an untrue feature 
intentionally, and doing so in the service of a message. Grasping the intended referent allows the viewer to understand the significance - the rationale-of what otherwise would be an error in the picture. Such pictures may be described as metaphors (Kennedy, 1982). Most readers will be familiar with the idea of linguistic metaphor [e.g., a sentence in which one item (e.g., 'man') is stated to be a second (e.g., 'wolf'), with properties of the second ('seeks prey') used to explain properties of the first]. Perhaps the idea of visual metaphor might not be quite as familiar. What it means to be a visual metaphor can be elaborated in parallel with our claim about verbal metaphor: one item (e.g., 'the Over-the-Top Leader') is portrayed, unrealistically, as having the properties of another ('Pinocchio's nose') to suggest the first has relevant features true of the second ('untruthful').

We have shown pictures like the Gericault, and reprints of nineteenthcentury prints, to friends and when we asked pointedly about speed and realism, we found the pictures were described as showing horses moving fast, but in an unrealistic way. The present paper reports experiments testing whether this description is general.

Arnheim (1974) discussed motion representation at length, and its aesthetics (which here we will touch on rather sparsely as matters to do with 'liking'). In painting, sculpture, and photography, he noted, the viewer frequently takes fake postures depicting locomotion to be realistic. "The conventional attitude of the galloping horse with outstretched legs, as seen in Gericault's Derby at Epsom [works] for only the maximum spread of the legs translated the intensity of the physical motion into pictorial dynamics, even though no running horse can ever assume that position except during a leap" (Arnheim, 1974, p. 423-424). (See Note 1 on the actual poses in a leap).

Realistic or not, of interest, Arnheim (1974), a keen Gestalt theorist, argued that the dynamic characteristics (Dobrez, 2013; Hubbard and Ruppel, 2017) perceived in a picture derive from the lines, shapes and directions on the bidimensional surface rather than from familiarity with real postures. For example, limbs with acute angles, presented as diagonals, might suggest motion. A runner is often shown with arms bent, and the Ford Mustang running-pony badge has a foreleg bent at the knee in an acute angle, and a rear leg meets the horizontal body at $45^{\circ}$. Likewise, a wedge shape, such as an isosceles triangle, in an oblique position, may suggest motion-in-depth with the point of the triangle taken to be receding afar, and the convergence of long sides of the triangle suggesting diminution due to perspective (Hammad and Kennedy, 2017; Mastandrea and Kennedy, 2016; Mastandrea et al., 2014). The triangle is readily taken as pointing (Attneave, 1971) and suggests a direction of motion. Arnheim's analysis leads to the conjecture that the fake gallop contains shapes that suggest very fast motion despite being unrealistic. We will test this conjecture, using equestrians and observers much less familiar with horses, 
and ask if observers report speedy motion, even if they detect that the fake gallop is unrealistic.

Of interest, studies indicate that pictures that suggest motion may give rise to actual impressions of speed (Di Dio et al., 2016; Mastandrea and Umiltà, 2016). Burr and Ross (2002) suggest that traces left by a moving object (including speed lines in a static picture), indicate the direction of movement to vision (Juricevic, 2017; Kennedy, 1982), but in addition brain areas processing real motion are activated by implied-motion pictures (Kim and Blake, 2007; Osaka et al., 2010; Pavan et al., 2011; Williams and Wright, 2010). Kourtzi and Kanwisher (2000), using fMRI, found strong activation of the V5/Medial Temporal and Medial Superior Temporal cortex by static pictures depicting implied motion, compared to pictures of static objects. Cattaneo et al. (2017) found that V5 activity is related to motion represented in abstract artworks. Further, memory for the content pictured in a 'freeze frame' is displaced in the direction of implied motion in studies of 'representational momentum' using frozen-action photographs (Hubbard, 2005).

Arnheim (1974) wrote about 'pictorial dynamics' and suggested they boost appreciation of artwork i.e. 'liking', in the present context (Mastandrea and Maricchiolo, 2014). If so, the amount of movement reported in viewing horse pictures could correlate positively with 'liking' ratings. We examine this suggestion here. It is a testable proposition, but in the absence of a rationale that not only links estimated speed to positive emotion, but also connects static postures with less emotion, there is room for doubt. Liking-ratings of horse pictures in particular can be products of several factors. Surely poses can be portrayed with positive or negative expression. The emotion suggested by the artists' versions of a posture may be what is highly influential, more so than speed.

Further, rather than using Arnheim's phrase "intensity of physical motion", we asked observers about the 'amount of motion' suggested by pictures. 'Amount' may suggest speed more readily than 'intensity'.

In Experiment 1 we sampled a wide range of artwork paintings as stimuli, since the conjecture about horses galloping arose in this context. The sample is highly diverse, but this may help the study to be relevant to the art world, and motion depiction in art, much as Hubbard and Ruppel (2017) sampled and tested pictures of cave art in studying early sketches and apparent motion.

\section{Experiment 1}

The Gericault painting was included in Experiment 1, and the pictures in Experiment 1 were selected to represent horses with five gaits. Also, in Experiment 1 we tested equestrians and observers less accustomed to horses. It may be that observers with different levels of familiarity with horses find the portrayed gaits, including fake gallop, effective. If Arnheim's conjecture 
is correct, the faster the horse the more the image is liked. Alternatively, the fake gallop in particular might be deemed inappropriate by participants highly familiar with horses ('experts'), even if it is accepted by those unfamiliar with horses ('novices'). We wondered if the experts would find the pose unappealing, perhaps even ambiguous, since it might best fit postures such as stretching. (In Experiment 2, silhouettes of horses control for the variety of artwork factors in Experiment 1 and help determine whether the pose is effective in the absence of the details of scenes such as jockeys and shadows. Also, in Experiment 2 observers were asked to judge the realism of the poses).

Experiment 1 included ratings of 'levade,' a prancing or rearing posture of the horse. The horse is not moving forward in levade. [Notably, Jacques-Louis David's famed 1801 Napoleon Crossing the Alps (17 in the Appendix) uses the levade pose, as does 18, the exceptionally impressive Stubbs Whistlejacket]. Inclusion of this posture might help mask the intentions of the experiment. Levade is an energetic posture, more demanding than a walk, conveying less speed than a gallop. (If Arnheim's term 'intensity'had been offered to observers, ambiguity might have been introduced. Levade is low in speed but high in 'intensity').

Observers were recruited and tested in accord with human-participant practices of the Education Department, Roma Tre University.

\subsection{Method}

\subsubsection{Participants}

One hundred participants were tested: a group of 41 equestrians ('experts', recruited at an equestrian center in Rome) and a group of 59 naïve participants ('non-experts', students of Education at the University of Roma Tre, Rome) volunteered for the experiment. 'Experts' were people who have been riding a horse for several years and the naïve participants had never ridden a horse or had only an occasional ride. The age range was between 14 and 61 (61 women, 39 men; mean 35.2, SD 13.6). Participants had normal or corrected-to-normal vision and were naive about the purpose of the experiment.

\subsubsection{Stimuli}

Fifteen paintings of different art styles covered five gaits. Four realistic gaits were alt (meaning 'halt' or 'standing'), walk, trot and gallop. Paintings exemplifying these, plus paintings showing the Gericault fake gallop, were selected by one author and a highly experienced equestrian. Three pictures with a levade posture were included, in which the horse stands on its hind legs, the front legs are in the air, and the horse is not moving forward with speed. The total was 18 pictures. The images were high-quality colored digital reproductions, scanned from books and acquired from the web. The proportions of the stimuli were in accord with the original format of each painting. The picture 
sizes and resolution in the display were between 8.9 and $16.1 \mathrm{~cm}$ in height and between 11.9 and $18.7 \mathrm{~cm}$ in width, with 36 dots per $\mathrm{cm}$.

The Gericault was presented in a broad artistic context, to increase the significance of our project to the art world, and to lessen the possibility that the Gericault pose would stand out as bolder or more energetic than the other paintings in our sample. The art styles ranged from prehistoric art (from Lascaux) to realistic, futurist and expressionist paintings (see the Appendix for a list of the paintings used). The horses in the pictures presented were all oriented to the right (showing their sides, chest to tail), to avoid any differences in motion from left/right directions; in some cases we had to flip the original paintings horizontally.

\subsubsection{Procedure}

Participants were seated in an isolated, dimly lit room, in front of a $48 \mathrm{~cm}$ computer monitor located at a distance of about $70 \mathrm{~cm}$ from the participant's head. The pictures were presented one at a time on the computer monitor. To randomize the presentation we used three different power-point slide shows. Participants answered two questions, in Italian, here translated as 1) whether movement was shown by the picture and if so how much and 2) the level of liking of each image [both questions on an 11-point Likert scale, from 0 (low) to 10 (high)]. Every participant was given a booklet; each page contained the two written questions. After the exposure to each image, participants were required to respond to the questions by checking a number on the 11-point scale, with no time limit. Once the assessment of one stimulus was completed he/she had to press the enter button to move to the next image and turn the booklet to the next page to answer the same two questions; this task was performed for all the 18 stimuli. The duration of the experiment was about 10 minutes.

\subsection{Results}

Gaits that are associated with faster speed lead to higher levels of perceived movement (alt mean 1.4; SD 1.5, increasing steadily to mean 8.8, SD 1.6, for fake gallop; see Fig. 2). Mean scores for motion shown and liking, for each gait, were distinguished for the two groups, expert and novice. The experimental design was a mixed within/between factorial design: 5 (different gaits, within participants) $\times 2$ (levels of expertise, expert and novice, between groups). The data were submitted to a mixed model (within/between) ANOVA for repeated measures. The main effect of gait was significant $F(4$, $\left.392)=339.9 ; p<0.001, \eta^{2}=.776\right)$. The main effect of expertise was also significant $\left(F(1,98)=4.205, p<.05, \eta^{2}=0.043\right)$ : experts gave higher scores than novices, except for alt; however this difference was significant only for gallop $[t(99)-3.127, p<0.001]$ and fake gallop $[t(99)-1.946, p<0.05]$ as shown 


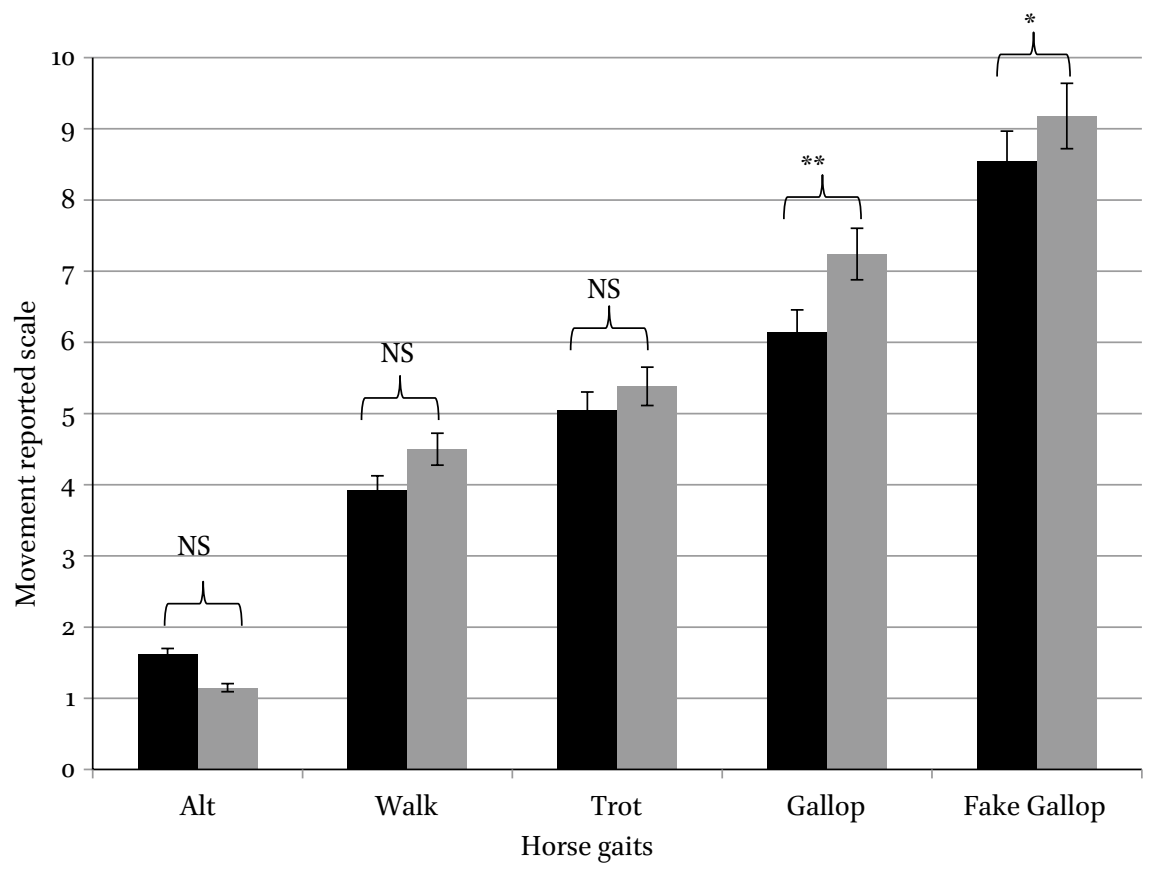

Non experts Experts

Figure 2. Mean scores (vertical scale) for motion reported from alt to fake gallop (error bars indicate standard errors of the means; $* p<0.05 ; * * p<0.01$ ).

in Fig. 2. With a Bonferroni correction for multiple comparisons, the experts still give significant higher scores for gallop. Confidence in this result follows from the two-way interaction being significant $F(4,392)=3.592 ; p<0.01$ $\left(\eta^{2}=0.776\right)$.

Liking scores generally increased, but only slightly, with faster gait (Fig. 3), from alt $(M=5.8$, SD 1.9) to fake gallop ( $M=6.7$, SD 1.4), though trot was liked less than walk, numerically. The main effect of gait was significant $[F(4$, $\left.392)=5.132, p<0.001, \eta^{2}=0.050\right]$. The effect may be modest because all the horse pictures appealed moderately to both the general public and equestrians. The range (from 5.8 to 6.7) is less than one step on the 11-step scale. This helps make sense of the fact that the main effect of expertise (experts vs. novices) was not significant $\left[F(1,98)=0.55, p=0.816, \eta^{2}=0.001\right]$, and also that the two-way interaction was not significant $[F(4,392)=0.687, p=0.601$, $\left.\eta^{2}=0.007\right]$. In both groups, the two gallop gaits (real and fake) are the most appreciated, numerically. 


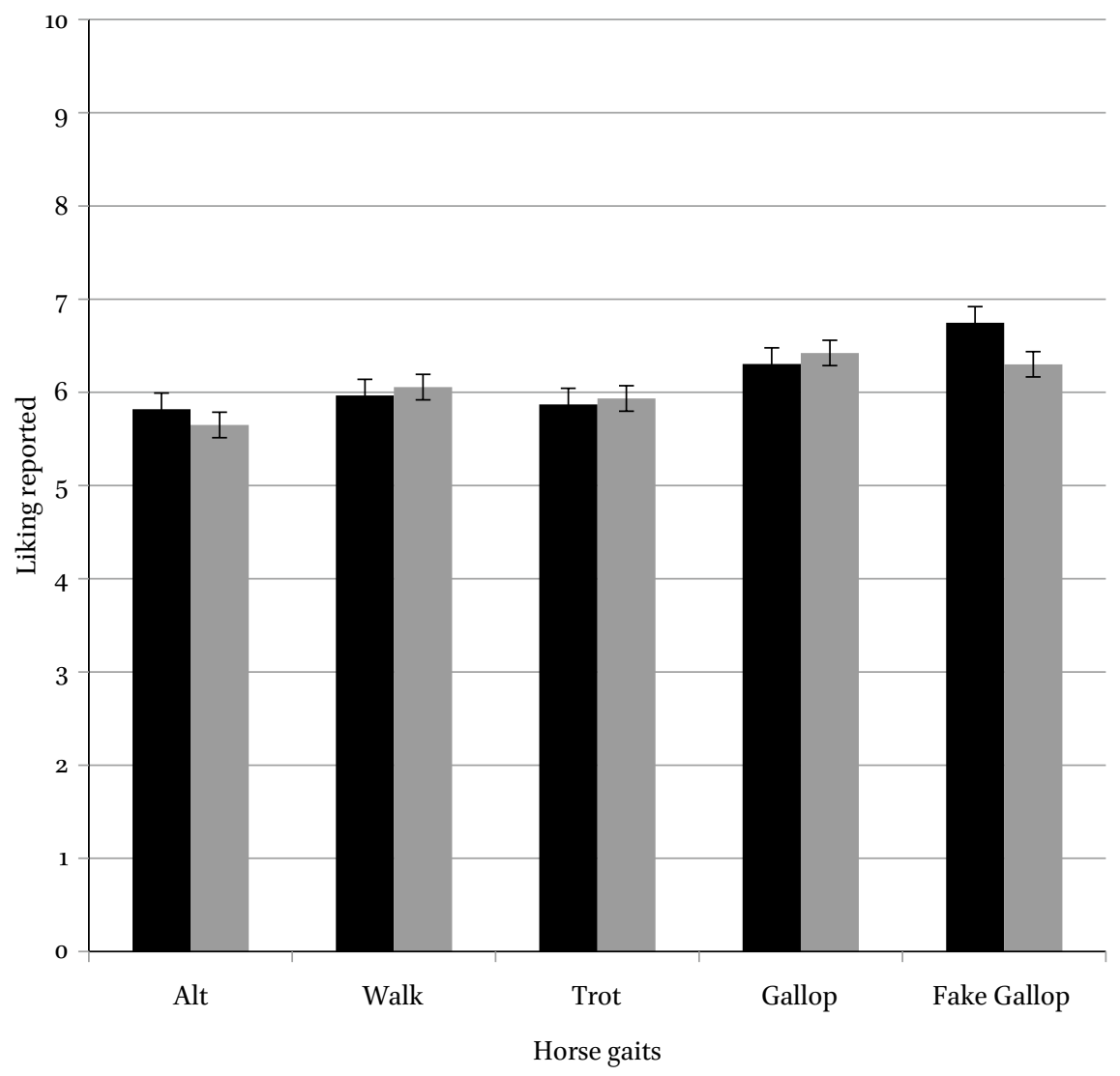

Non experts Experts

Figure 3. Mean scores for 'liking' from alt to fake gallop (error bars indicate standard errors of the means).

\subsection{Discussion}

The gait pictures produce reports of motion-shown, likely meaning higher apparent speed, from the alt gait (static) to gallop (fastest realistic motion), and then higher still to fake gallop (the pose at issue). Also, the faster the gait, the higher the liking score, albeit truly quite modestly, from experts and naïve observers alike. At less than one step, support for Arnheim's conjecture that speed entrains liking is quite limited. This is surely a modest effect in part, it is quite likely, because artwork, and horse pictures in particular, are generally moderately attractive. Only a minority are strikingly appealing or highly unpleasant. 
Of note, experts, despite having considerable direct experience with horses, gave the fake gallop pictures significantly higher movement scores than naïve participants. This fits with Arnheim's comments that pictures convey motion despite being unrealistic, even to observers experienced with the subject matter, equestrians in this case. However, this intriguing finding might be explained in several ways. On the one hand, it may be the posture is deemed realistic by experts and novices. If so, one wonders why there was considerable discussion of this fake posture in the nineteenth century, and its features were of great interest in photography as a way to decide whether the pose was realistic (Muybridge, 1878). On the other hand, it may be that both naïve and expert observers take it as unrealistic. Many pictures are effective representations despite being unrealistic, using devices such as exaggeration and speed lines (Chao \& Kennedy, 2015; Cutting, 2002; Kennedy, 1982). This is the subject of Experiment 2.

In Experiment 2, we used simple silhouettes specifically designed for the experiment. These remove many of the variables in artworks e.g., color, shading, ground surface, perspective and expression. Will leg extension affect represented speed and liking similarly in artwork and in schematic stimuli?

\section{Experiment 2-Silhouettes}

Experiment 1 tested the Gericault pose in the context of artwork. However, to reduce the heterogeneity in the stimuli (e.g., in matters of style), and to ensure that scene factors (e.g., jockeys and shadows) were minimized, we conducted a second experiment with five horse silhouettes, one for each of the five gaits as before, created by a professional graphic designer (Fig. 4). In these pictures the horse body and head posture were similar across the stimuli, and what was changed was the extension of the legs. However, in fake gallop the horse's tail had to be inclined so as to avoid overlap with the extended rear legs, and the contour for the horse's chest became less as the foreleg extended. A highly experienced equestrian judged the portrayal of 4 gaits (alt, walk, trot and gallop) realistic. By this measure (relevant and repeatable but subjective), the only unrealistic silhouette was the Gericault-pose fake gallop.
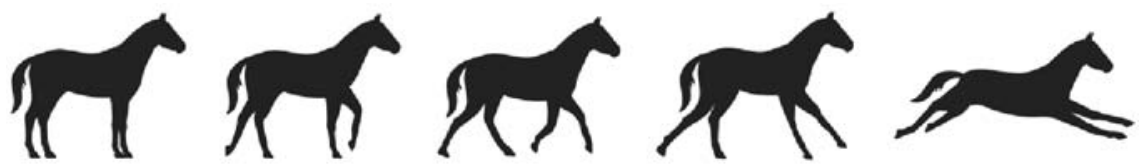

Figure 4. Silhouettes used in Experiment 2. From left to right: Alt, walk, trot, gallop, fake gallop. 


\subsection{Method}

\subsubsection{Participants}

Thirty participants (students of the Department of Education of the University of Roma Tre, non-expert in equestrian sport) were tested. The age range was between 20 and 29 (17 women, 13 men; mean 24.8, SD 2.5). Participants had normal or corrected-to-normal vision and were naive about the purpose of the experiment.

\subsubsection{Stimuli}

Five horse silhouettes covering five gaits (the four realistic postures, alt, walk, trot, gallop, plus the fake gallop 'à la Gericault') were created (see Fig. 4). Maximizing extension, the 'fake gallop' fore legs are straight, as in the Finishing Touch of Kentucky brooch. As in the Summers (1871a,b) prints, the fore hoofs are tilted (20-35 degrees). The body of the horse was largely constant as the leg extensions changed. The tail is elevated in fake gallop, and chest, belly and rear contours varied slightly as the legs elevated as a result of limb extension. Necessarily, there is less chest contour and more belly contour as the legs elevate. We did not vary other posture factors (for example, the stretching of the horse neck, the leaning of the body, etc.) that are related to forward gaits. This we leave for further experiments. The leg-extension/horse-body-length proportions for the gaits were $67 \%$ (alt), 82\%, 101\%, 124\% and 155\% (fake gallop), measuring the leg extensions from fore to rear hoof. The horse-bodylength was taken as chest to rear, from (1) the contact point of the body with the lower contour of the tail to (2) the chest contour horizontal to that contact point. The measures of leg extension were taken from the front of the front hoof to the rear of the rear hoof. We did not use levade. Clear results (and personal observation) of Experiment 1 suggested it was not needed.

The silhouettes used were black-and-white digital pictures, presented on a monitor. The pictures presented were all oriented to the right, to avoid any differences in motion from left/right directions.

\subsubsection{Procedure}

Participants were reached on-line, through the social group of the Department of Education. They were invited to participate in the experiment through the Google Form platform. Once they agreed they had to click on the link that connected them to the experimental script. In the first page they read the instructions followed by the five pictures of the horse gaits. The five pictures were presented in three different gait orders, none of which was alt/walk/trot/gallop/fake gallop. For each picture they had to answer a question on motion and a question on liking, as in Experiment 1, by checking a number. Participants were offered a five-point scale, with no time limit. (We 
reduced the options from 11 in Experiment 1, thinking that a five-option scale is sufficient to test our hypotheses). In addition, the participants were asked if the horse gaits depicted by the silhouette were realistic, rating the realism on a five-point scale. Once the assessment of one stimulus was complete he/she moved to the next image and answered the same two questions.

\subsection{Results}

Mean scores for motion reported are in Fig. 5, and for motion reported, liking and realism in Table 1.

The experimental design was a within-participants factorial design with five different gaits (alt, walk, trot, gallop, fake gallop). Mean scores of the motion reported for each gait were submitted to a within-model ANOVA for repeated measures. Faster gaits were associated with higher motion reported-the main effect of the analysis of variance for repeated measures was significant $\left[F(4,116)=29.5, p<0.001, \eta^{2}=0.505\right)$. Paired $t$-tests comparing the gaits in planned comparisons also found faster gaits giving reports of higher speed: alt vs. walk $[t(29)=-1.81, p=0.07]$; walk vs. trot $[t(29)=-4.45, p<0.001]$; trot vs. gallop $[t(29)=-2.18, p<0.05]$; gallop vs. fake gallop $[t(29)=-2.036$, $p<0.05]$. With a Bonferroni correction, walk vs. trot remains significant.

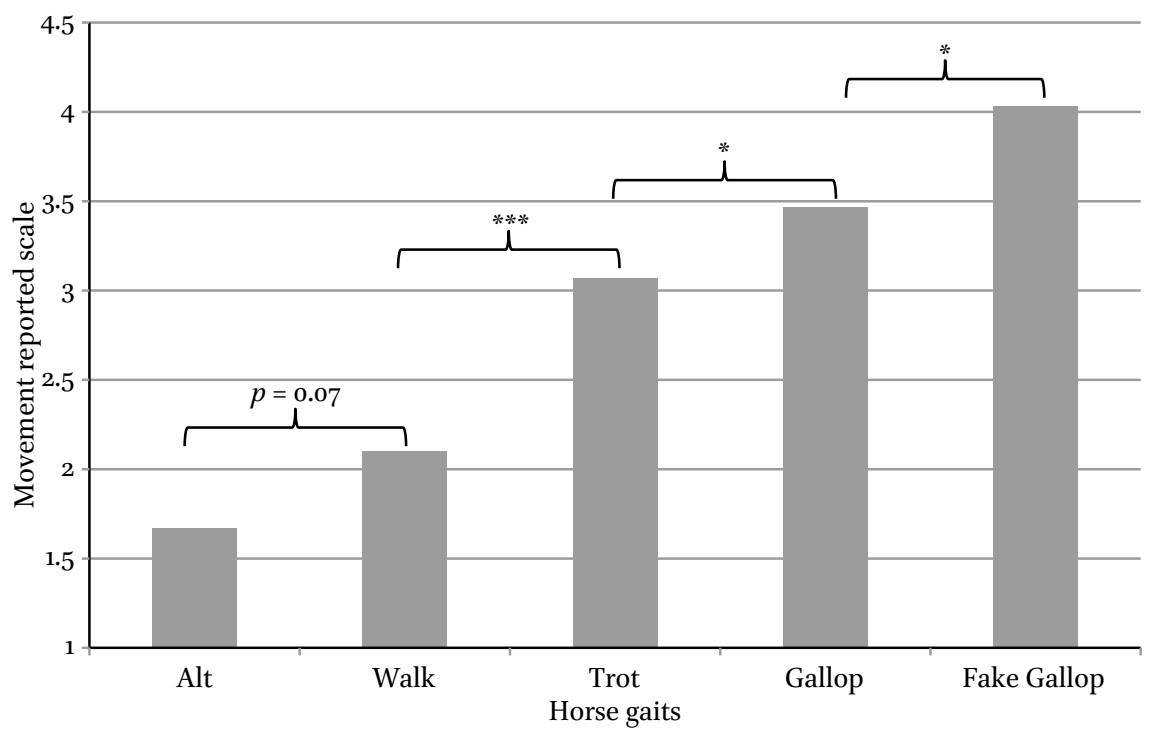

Figure 5. Mean scores for motion reported from alt to fake gallop (error bars indicate standard errors of the means; $* p<0.05 ; * * * p<0.001$ ). 
Table 1.

Mean scores (and SD in parentheses, on a five-point scale) for motion perceived, liking and realism for each gait.

\begin{tabular}{|c|c|c|c|c|}
\hline Silhouette & Gaits & $\begin{array}{c}\text { Motion } \\
\text { perceived }\end{array}$ & Liking & Realistic \\
\hline & Alt & $\begin{array}{c}1.67 \\
(1.02)\end{array}$ & $\begin{array}{c}3.2 \\
(0.72)\end{array}$ & $\begin{array}{l}3.16 \\
(1.44)\end{array}$ \\
\hline & Walk & $\begin{array}{c}2.1 \\
(0.84)\end{array}$ & $\begin{array}{c}3.0 \\
(1.2)\end{array}$ & $\begin{array}{c}3.5 \\
(1.4)\end{array}$ \\
\hline & Trot & $\begin{array}{c}3.06 \\
(0.69)\end{array}$ & $\begin{array}{c}3.3 \\
(0.87)\end{array}$ & $\begin{array}{c}3.7 \\
(1.02)\end{array}$ \\
\hline & Gallop & $\begin{array}{c}3.46 \\
(1.07)\end{array}$ & $\begin{array}{c}2.73 \\
(1.36)\end{array}$ & $\begin{array}{c}3.0 \\
(1.43)\end{array}$ \\
\hline & $\begin{array}{l}\text { Fake } \\
\text { Gallop }\end{array}$ & $\begin{array}{c}4.03 \\
(1.29)\end{array}$ & $\begin{array}{c}2.73 \\
(1.28)\end{array}$ & $\begin{array}{c}2.3 \\
(1.26)\end{array}$ \\
\hline
\end{tabular}

The liking scores, contrary to Experiment 1, decreased slightly for the faster gaits, with the highest score being for $\operatorname{trot}(M=3.3$, SD .87), and the lowest scores for gallop and fake gallop (both $M=2.73$ ); the main effect of the analysis of variance for repeated measures was significant $[F(4,116)=2.44$, $p<0.05, \eta^{2}=0.078$ ).

Fake gallop was judged least realistic. The mean scores for realism of the different gaits rise numerically from alt $(M=3.16$, SD 1.44$)$, to walk $(M=3.5$, 
SD 1.4), and trot $(M=3.7$, SD 1.02), and fall to gallop $(M=3.0$, SD 1.43), offering a modest range, but, of interest, they fall still further to the lowest score for fake gallop ( $M=2.3$, SD 1.26), as far below gallop (0.7) as gallop is below trot. The main effect of the analysis of variance for repeated measures was significant $\left[F(4,116)=6.27, p<0.001, \eta^{2}=0.178\right)$; paired $t$-tests comparing scores for realism of the postures found: trot vs. gallop $[t(29)=2.91$, $p<0.01]$; trot vs. fake gallop $[t(29)=5.66, p<0.001]$; and gallop vs. fake gallop $[t(29)=2.19, p<0.05]$, with the consequence that not only was the low score for fake gallop $(M=2.3)$ significantly less realistic than trot, the highest score, but it was also significantly less than the next-lowest score, gallop $(M=3.0)$. With a Bonferroni correction, trot vs. fake gallop remains significant. Of further interest, despite the unrealistic impression of fake gallop, the motion reported increased steadily from alt to fake gallop.

\subsection{Discussion}

With silhouettes, Experiment 2 confirmed the reported-motion findings of Experiment 1. Faster gait lead to higher motion scores, approaching ceiling ( $M=1.67$ for alt to 4.3 out of 5 for fake gallop), meaning observers used most of the full scale. However, unlike Experiment 1, the high-speed gait was liked least (2.3 out of 5 for fake gallop compared to 3.7 for trot). Arnheim's conjecture that liking increases with amount of motion is contradicted. The motions shown in artwork may often be allied with features conveying positive expression and the plethora of features may have produced a modest but spurious connection between liking and faster gait in Experiment 1. Artists can convey positive and negative emotions along with any gait, surely. For example, Paul Delaroche painted the same subject as David: Napoleon crossing the Alps. David's picture uses levade, and suggests intense drama, but levade can be used to suggest fear, e.g., avoiding a snake on the ground. Delaroche's 1850 picture has a horse walking, and the mood is somber-the horse's head hangs, and Napoleon's arms are lowered. A horse can be drawn as sprightly or as weary, frightened or eager, skittish or lively, and these positive or negative tones may be what matter most for 'liking', not speed.

Mean liking scores in Experiment 2 were like those of Experiment 1, in the middle of the scale (about 2.73 to 3.3 out of 5-not much range, as in Experiment 1). Both experiments have restricted ranges, even if Experiment 1 's artwork had many more features on which to base judgments. Hence, there is no clear evidence across experiments that 'dynamic' faster gaits are liked more. Indeed, many equestrian representations show horses simply standing. Further, the most famous and admired Stubbs painting of a horse (number 18 in the Appendix, Whistlejacket, National Gallery, London, UK, a breathtaking 
image in its time and still today perhaps) shows levade, prancing not galloping (Vaughan, 1999). At best, the hypothesis that faster motion and increases in liking are linked should be doubted. Indeed, stillness and contemplation may be as appealing, in its own way, as dynamism and direction.

\section{General Discussion}

Horse gaits such as walk, trot and gallop use different horizontal limb extensions, and vision may respond to this as information for motion, the more extended the limbs the greater the apparent speed, as Arnheim (1974) suggested. Of note, three forward-movement postures here are realistic (and motion-reported scores increase accordingly). The information for motion may be provided by key features of the correct form including a sequence of increasing leg extensions. Such a sequence can readily be extrapolated beyond realistic limits, as in exaggeration (producing hyperbole or, taken too far, caricature). If the features are exaggerations that observers deem unrealistic, we suggest the pictures can be described as hyperboles, a species of metaphor (Cutting, 2002; Kennedy, 1982; Rhodes et al., 1987).

Extension may be a useful factor in conveying motion in pictures of dancers, skaters, skiers, diving birds, squids and many other mobile creatures. For example in a dance, shown in freeze frames, leg and arm extensions might imply motion - the more extended the more dynamism. (In motion pictures, in contrast, impressive speed is evident in 'tuck' positions of divers, skaters and aerobatic snowboarders. Skaters, for example, draw their arms in to the body, or raise their arms straight above their head, to increase their rate of spin to a visual blur). In many cases pictures with extreme extension of dancers would be realistic, since dances use the full range of limb motion. But this does not apply to horses. Further, it does not apply to galloping giraffes or zebras. In future experiments, it would be helpful to ask observers to single out the features they find unrealistic. Is it the amount of the limb extension? Would slightly less extension be accepted? Is the symmetry of the forelegs with the rear legs of concern? Is one fore leg in full extension-just one, not two-acceptable? Does the same apply to the rear leg? Also, in the running-pony curled-leg posture - the opposite of a fake gallop - the legs can be more or less curled. (In both fake gallop and running-pony poses the horse is off the ground). Is an extreme curl as good as extreme extension in suggesting speed? Perhaps observers are reacting to the use of extremes along a dimension, and both ends of the dimension have equal value in implying speed.

Of interest, for many animals, extensions similar to the Gericault horse are entirely appropriate. In a chase, hunting animals such as cats extend fore legs while the rear legs stretch out behind. Pouncing on a prey animal with two outstretched forelimbs would be highly effective. Extension in the form of 
outstretched limbs is evident in dogs too, so the pose is not restricted to felines. Some prey animals use the Gericault pose-rabbits and hares for example. Flying squirrels have a fairly similar pose. Ideally, observers should deem outstretched poses of many animals as suggesting fast motion, and fully realistic, without any use of metaphor. This interesting possibility suggests a role for familiarity. For particular animals many observers may recognize the Gericault pose is close to realistic, and generally in keeping with energetics-that is, physiological, ecological dynamics. They may take it that the pose has been 'borrowed' from those cases and, in the case of horses, inserted where it is fake. In language, 'heart of stone' has this character. 'Stone' is used because it is truly unyielding in the real instance, and it is borrowed to mean unrelenting.

In sum, in a Gericault galloping-horse picture, important in the history of art, leg extension to the fore and rear depicts fast motion successfully. Popular debates over horse postures in art in the nineteenth century may reflect not only this indicator of motion, but also judgments that the extension has gone too far to be realistic.

\section{Acknowledgments}

We thank Alessandra Capra for research assistance and Lucia Caruso for the horse silhouettes drawings.

\section{Note}

1. Even when it jumps, generally the horse's four legs are not stretched outward simultaneously like those in Gericault's painting Derby at Epsom. In the standard jump sequence (Fig. A), the horse movements are: 1. Taking off, with the front legs folded near the chest and the hind legs stretched backward (having just given the thrust on the ground); 2. Suspension over the fence, with the front legs starting to be stretched forward and the back legs starting to be folded toward the body; 3. Landing, with the front legs stretched forward and hind legs folded.

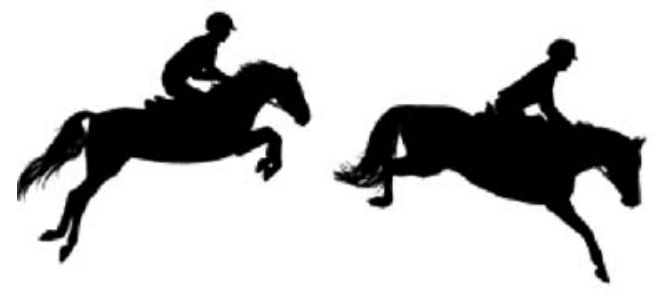

Figure A. Postures of leaping horse. 


\section{References}

American Indian Wars (n.d.). Retrieved October 18, 2017, from https://en.wikipedia.org/wiki/ American_Indian_Wars.

Arnheim, R. (1974). Art and Visual Perception, University of California Press, Berkeley, CA, USA.

Attneave, F. (1971). Multistability in perception, Sci. Am. 225(6), 62-71.

Burr, D. C. and Ross, J. (2002). Direct evidence that "speedlines" influence motion mechanisms, J. Neurosci. 22, 8661-8664.

Cattaneo, Z., Schiavi, S., Silvanto, J. and Nadal, M. (2017). A TMS study on the contribution of visual area V5 to the perception of implied motion in art and its appreciation, Cogn. Neurosci. 8, 59-68.

Chao, H. Y. and Kennedy, J. M. (2015). Metaphoric car drawings by a 12-year-old congenitally blind girl, Perception 44, 1349-1355.

Cutting, J. E. (2002). Representing motion in a static image: Constraints and parallel in art, science and popular culture, Perception 10, 1165-1193.

Di Dio, C., Ardizzi, M., Massaro, D., Di Cesare, G., Gilli, G., Marchetti, A. and Gallese, V. (2016). Human, nature, dynamism: The effects of content and movement perception on brain activations during the aesthetic judgment of representational paintings, Front. Hum. Neurosci. 9, 705. doi: 10.3389/fnhum.2015.00705.

Dobrez, L. (2013). The perception of depicted motion, Arts 2, 383-446.

Goldstein, B. E. (2007). Sensation and Perception, Wadsworth Publishing, Belmont, CA, USA. Gombrich, E. H. (1964). Moment and movement in art, J. Warburg Courtauld Inst. 27, 293-306. Gombrich, E. H. (1995). The Story of Art, $16^{\text {th }}$ ed., Phaidon Press, London, UK.

Hammad, S. and Kennedy, J. M. (2017). The picture surface illusion: 3D biases 2D, in: The Oxford Compendium of Visual Illusions, A. Shapiro and D. Todorovic (Eds), pp. 209-213, Oxford University Press, Oxford, UK.

Hubbard, T. L. (2005). Representational momentum and related displacements in spatial memory: A review of the findings, Psychonom. Bull. Rev. 12, 822-851. doi: 10.3758/ bf03196775.

Hubbard, T. L. and Ruppel, S. E. (2017). The (dynamic) mind in the cave: Representational space of cave paintings and petroglyphs, Emp. Stud. Arts 35, 67-92.

Juricevic, I. (2017). Analysis of pictorial metaphors in comic-book art: Test of the LA-MOAD theory, J. Graphic Novels Comics, 1-21. doi: 10.1080/21504857.2017.1413667.

Kennedy, J. M. (1982). Metaphor in pictures, Perception 11, 589-605.

Kim, C. Y. and Blake, R. (2007). Brain activity accompanying perception of implied motion in abstract paintings, Spat. Vis. 20, 545-560.

Korol, T. (2017). Photo, Globe and Mail, July 17, 2017, Section S, p. 1.

Kourtzi, Z. and Kanwisher, N. (2000). Activation in human MT/MST by static images with implied motion, J. Cogn. Neurosci. 12, 48-55.

Mastandrea, S. and Kennedy, J. M. (2016). Pot/lid illusion, i-Perception 7. doi: 10.1177/ 2041669516665622.

Mastandrea, S. and Maricchiolo, F. (2014). Implicit and explicit aesthetic evaluation of design objects. Art Percept. 2, 141-162.

Mastandrea, S. and Umiltà, M. A. (2016). Futurist art: Motion and aesthetics as a function of title, Front. Hum. Neurosci. 10, 201. doi: 10.3389/fnhum.2016.00201. 
Mastandrea, S., Kennedy, J. M. and Wnuczko, M. (2014). Picture surface illusions: Minor effects on a major axis, Perception, 43, 23-30.

Muybridge, E. J. (1878). The science of the horse's motion, Sci. Am. 39, 241.

Osaka, N., Matsuyoshia, D. and Ikeda, T. (2010). Implied motion because of instability in Hokusai Manga activates the human motion-sensitive extrastriate visual cortex: An fMRI study of the impact of visual art, Neuro Report 21, 264-267.

Pavan, A., Cuturi, F. L., Maniglia, M., Casco, C., Campana, G. and Maniglia, M. (2011). Implied motion from static photographs influences the perceived position of stationary objects, Vis. Res. 51, 187-194.

Rhodes, G., Brennan, S. and Carey, S. (1987). Identification and ratings of caricatures: Implications for mental representations of faces, Cogn. Psychol. 19, 473-497.

Summers, W. (1871a). Tattenham Corner, published April $21^{\text {st }}$ by J. M. McQueen, London, UK, and Paris, France.

Summers, W. (1871b) The Winning Post, published April 21 ${ }^{\text {st }}$ by J. M. McQueen, London, UK, and Paris, France.

Vaughan, W. (1999). British Painting: the Golden Age, Thames \& Hudson, London, UK.

Williams, A. L. and Wright, M. J. (2010). Static representations of speed and their neural correlates in human area MT/V5, Neuro Report 20, 1466-1470.

\section{Appendix}

List of paintings used in the experiment:

1. Franz Marc, Little blue horse, 1912, Saarland Museum, Germany (Alt).

2. Giulio Romano, Hall of the horses, 1526-1528, Palazzo Te, Mantua, Italy (Alt).

3. Franz Marc, Small horse study, 1905, Franz Marc Museum, Germania(Alt).

4. Max Liebermann, Boy on horse, private collection (Walk)

5. Giorgio De Chirico, Horse in a landscape, private collection (Walk)

6. Wassily Kandinskij, Couple riding, 1906-1907, Städtische Galerie im Lenbachhaus, Munich, Germany (Walk).

7. Jacques Laurent Agasse, A grey arab stallion in a wooded landscape, private collection (Trot).

8. Francisco José de Goya, Queen Maria Luisa on horseback, 1799, The Prado Museum, Madrid, Spain (Trot).

9. Rembrandt, The Polish rider, 1655, Frick Collection, New York (Trot).

10. Laurine Justus Pace, Afternoon run, 2009, private collection (Gallop).

11. Alessandro Bruschetti, Dynamism of horses, 1932, Private collection, Monza, Italy (Gallop). 
12. Pittura Rupestre, Cavallo, 15000-10000 B.C.E, Lascaux, France (Gallop).

13. Giovan Francesco Gonzaga, Horse riding on the beach, 1982, private collection (Fake gallop).

14. Théodore Géricault, Derby at Epsom, 1821, Louvre Museum, Paris (Fake gallop).

15. Giovanni Segantini, Galloping horse, 1888, Modern Art Gallery, Milan (Fake gallop).

16. Ludwig Koch, Die Cabriole, 1923, Art History Museum, Vienna, Austria (Levade).

17. Jacques-Louis David, Napoleon crossing the Alps, 1800, Chateau de Malmaison, Rueil-Malmaison, France (Levade).

18. George Stubbs, Whistlejacket, 1762, National Gallery, London, UK (Levade). 